\title{
Improved Agrobacterium rhizogenes-mediated hairy root culture system of Withania somnifera (L.) Dunal using sonication and heat treatment
}

\author{
Chandrasekaran Thilip ${ }^{1}$ Chellappan Soundar Raju' ${ }^{1}$ Kandhan Varutharaju ${ }^{1}$. \\ Abubakker Aslam ${ }^{1} \cdot$ Appakan Shajahan ${ }^{1}$
}

Received: 21 October 2014/Accepted: 16 March 2015/Published online: 26 March 2015

(C) The Author(s) 2015. This article is published with open access at Springerlink.com

\begin{abstract}
An improved Agrobacterium rhizogenes-mediated genetic transformation of Withania somnifera (L.) Dunal was developed using the bacterial strain R1000 with leaf segment explants of in vitro raised plantlets. Out of the three strains used (R1000, MTCC 2364 and MTCC 532), the strain R1000 proved to be more efficient than others. Among the different conditions tested, the highest (93.3\%) transformation rate was observed after 3 weeks when the explants were subjected to sonication $(15 \mathrm{~s})$ and heat treatment $\left(41^{\circ} \mathrm{C}\right.$ for $\left.5 \mathrm{~min}\right)$. Transgenic status of the hairy roots was confirmed by PCR using rol B-specific primers. HPLC analysis showed the ability of hairy roots to synthesize withaferin $\mathrm{A}$ and withanolide $\mathrm{A}$, both steroidal lactones of medicinal value. This protocol offers new avenue in A. rhizogenes-mediated hairy root induction and is useful for large-scale production of these bioactive compounds from $W$. somnifera.
\end{abstract}

Keywords Agrobacterium rhizogenes - Withania somnifera $\cdot$ Hairy roots $\cdot$ Withanolides $\cdot$ Sonication . Heat treatment

\section{Introduction}

Withania somnifera (L.) Dunal (Solanaceae) is an important medicinal plant which yields pharmaceutically active compounds called withanolides (Praveen and Murthy

Appakan Shajahan

shajahan.jmc@gmail.com

1 Plant Molecular Biology Laboratory, Department of Botany, Jamal Mohamed College, Tiruchirappalli 620 020,

Tamil Nadu, India
2012). They are chemically named as 22-hydroxy ergostane-26-oic acid 26, 22- $\delta$-lactones which are c-22-steroidel lactones (Sabir et al. 2011). Roots of W. somnifera contain major withanolides like withaferin $\mathrm{A}$ and withanolide A and they possess specific therapeutic properties. Withaferin A is recognized for its anticancer properties and is reported to inhibit cell growth of various human cancer cell lines including lung cancer-NCl-H46 (Choudhary et al. 2013). Withanolide A has recently been credited with a neotropic agent for recovery from nervous degeneration dendrites formation and its branching, and hence it can be a promising compound for the treatment of neural degeneration types of disease like Parkinson's and Alzheimer's disease (Kuboyama et al. 2005; Sabir et al. 2011). Other biological activities of $W$. somnifera include cholinesterase inhibition (Choudhary et al. 2004, 2005), anti-inflammatory via COX-2 enzyme inhibition (Jayaprakasam and Nair 2003), antibacterial activity and sex hormone deficiency regulation (Kiasalari et al. 2009), antiglycation (Maurya et al. 2008), and antipyretic activities (Ali et al. 1997).

Since the roots of $W$. somnifera contain a number of therapeutically applicable withanolides, mass cultivation of roots in vitro will be an efficient technique for the largescale production of this secondary metabolite. The development involves root culture system that would offer unique opportunity for producing root drug in the laboratory without having to depend on field condition. Such in vitro production of secondary metabolites helps to evade the problems related to genetic and epigenetic variations found in field-grown plants (Praveen and Murthy 2010). Further, constituents of withanolides have differed with the variety of tissue type and growth conditions in field (Sangwan et al. 2007). This causes difficulties in the compositional standardization of herbal formulations and the commercial exploitation of this plant (Chatterjee et al. 2010). 
A. rhizogenes-mediated hairy root production is an important tool for biosynthesis of valuable secondary metabolites like withanolides. Hairy roots are considered a very good system for continuous synthesis of valuable metabolic compounds in an aseptic condition in the absence of expensive growth regulators in the culture medium (Giri and Narasu 2000; $\mathrm{Hu}$ and $\mathrm{Du}$ 2006). For this reason, A. rhizogenes-mediated hairy root culture has been utilized in several pharmaceutically important plants for the production of secondary metabolites (Le Flem-Bonhomme et al. 2004; Zhao et al. 2004; Fu et al. 2005). However, A. rhizogenesmediated hairy root induction in $W$. somnifera is limited due to the lack of available and efficient hairy root induction procedure (Murthy et al. 2008; Sivanandhan et al. 2013). Alternative approaches for an efficient hairy root induction are valuable for large-scale production of withanolides.

Various efforts have been made to overcome problems associated with host/tissue to increase the number of infection sites, such as use of supervirulent Agrobacgerium strains and addition of some compounds to the co-cultivation medium. Recently, sonication-assisted Agrobacterium-mediated transformation (SAAT) attracts much attention in several plant species (Liu et al. 2005; Subramanyam et al. 2011). It has been successfully applied for hairy root production in Papaver somniferum (Le FlemBonhomme et al. 2004) and Verbascum xanthophoeniceum (Georgiev et al. 2011). It holds great promise for the enhancement of hairy root production. The advantage of this method is that the cavitations caused by sonication cause thousands of microwounds on the surface of the explants. These microwounds permit Agrobacterium to penetrate deeper and more completely throughout the explant than conventional wounding, increasing the probability of infection to host cells (Liu et al. 2005). Further, transformation efficiency in Agrobacterium was also improved in several plant species by the use of heat treatment (Khanna et al. 2004; Hiei et al. 2006; Gurel et al. 2009).

The present study was conducted with the major objective of improving the transformation efficiency of $A$. rhizogenes for hairy root production in $W$. somnifera by means of sonication and heat treatments. This system provides an efficient tool for attaining better transformation efficiency and is useful for commercial in vitro production of withanolides.

\section{Materials and methods}

\section{A. rhizogenes strains and hairy root induction}

A. rhizogenes strains (R1000, MTCC 2364 and MTCC 532) stored at $-80{ }^{\circ} \mathrm{C}$ were used for hairy root induction
(Saravanakumar et al. 2012). In order to induce hairy roots, overnight YEP (Yeast extracts peptone) liquid medium grown $\left(80 \mathrm{rpm}\right.$ at $28{ }^{\circ} \mathrm{C}$ for $16 \mathrm{~h}$; $\left.\mathrm{OD}_{600 \mathrm{~nm}}=1.0\right)$ bacterial suspensions were centrifuged at $8000 \mathrm{rpm}$ for $10 \mathrm{~min}$. For co-cultivation, leaves of 1-month-old in vitro grown plantlets of elite $W$. somnifera accession (ACCN 06) were cut along with midrib into small segments $(\sim 0.5 \mathrm{~cm} \times 0.5 \mathrm{~cm})$ and were transferred in Murashige and Skoog (1962) liquid medium containing bacterial suspension and $100 \mu \mathrm{M}$ acetosyringone for $30 \mathrm{~min}$ (Aslam et al. 2010; Mohamed Rafi et al. 2010). The pH of the medium was adjusted to $5.7 \pm 0.1$ before autoclaving at $121{ }^{\circ} \mathrm{C}$ and $104 \mathrm{~K} \mathrm{~Pa}$ for $15 \mathrm{~min}$. After removing the excessive bacteria culture with MS liquid medium and dried on sterile filter paper (Whatman No. 1), the transformed explants were placed on MS solid medium [0.8\% agar (w/v); Sigma-Aldrich] containing petri dishes for 2 days at $25 \pm 2{ }^{\circ} \mathrm{C}$ in darkness. Two days after co-cultivation, explants were placed on MS basal medium supplemented with $200 \mathrm{mg} \mathrm{l}^{-1}$ cefotaxime (Duchefa Biochemie, Netherlands). Further, these explants were subcultured on the same medium at 2 days intervals and the hairy rootinduced explants were counted for the analysis of transformation efficiency. Transformation efficiency (\%) was calculated as total number of explants which induced hairy roots/total number of explants cultured $\times 100$.

\section{Sonication and heat treatment on hairy root induction}

In order to analyze the influence of heat treatment on transformation efficiency of $A$. rhizogenes, explants were immersed in MS liquid medium containing strain R1000 suspension with $100 \mu \mathrm{M}$ acetosyringone and they were incubated on different temperatures of 39,41 , or $43^{\circ} \mathrm{C}$ for $3,5,7$, or $10 \mathrm{~min}$. After heat treatment, explants were incubated at $25 \pm 2{ }^{\circ} \mathrm{C}$ for $20 \mathrm{~min}$ and co-cultivated on MS solid medium for 2 days. Then these explants were cultured on hairy root induction medium $200 \mathrm{mg} \mathrm{l}^{-1}$ cefotaxime to induce hairy roots.

For sonication, the tubes containing leaf explants in the abovesaid condition were placed on sonicator (U1trasonic bath sonicator, PCI Analytics Pvt Ltd ${ }^{\circledR}$, Mumbai, India) for $5,10,15$, or $20 \mathrm{~s}$ sonication followed by heat treatment at $41{ }^{\circ} \mathrm{C}$ for $5 \mathrm{~min}$. Then they were incubated $25 \pm 2{ }^{\circ} \mathrm{C}$ for $20 \mathrm{~min}$. The infected explants were further co-cultivated on MS solid medium for 2 days. The co-cultivated explants were inoculated on MS solid medium amended with cefotaxime (200 $\mathrm{mg}^{-1}$ ) and subcultured at an interval of 2 days to induce hairy roots. The efficiency of transformation was recorded after 3 weeks. 


\section{PCR analysis of transgenic roots}

The Polymerase chain reaction (PCR) was used to detect the Ri T-DNA integration in the plant genome (Eppendorf Mastercycler $^{\circledR}$, Germany). Genomic DNA from transformed hairy roots as well as non-transformed roots (normal root from in vitro plants as negative control) was extracted by CTAB method as mentioned by Saravanakumar et al. (2012). Plasmid DNA from A. rhizogenes was isolated as described by Bulgakov et al. (1998) and used as positive control. PCR amplification was performed to detect the $423 \mathrm{bp} \mathrm{rol} \mathrm{B}$ gene fragment using specific primer set: forward primer $5^{\prime}$ GCTCTTGCAGTGCTAGATTT $3^{\prime}$ and reverse primer $5^{\prime}$ GAAGGTGCAAGCTACCTCTC $3^{\prime}$. The amplification reaction volume was $25 \mu \mathrm{l}$ using PCR buffer containing $1.5 \mathrm{mM} \mathrm{MgCl}_{2}, 200 \mu \mathrm{M}$ of each dNTPs, $200 \mathrm{pM}$ each of primers, $100 \mathrm{ng}$ genomic DNA, and $2 \mathrm{U}$ Taq polymerase. The PCR conditions were $94{ }^{\circ} \mathrm{C}$ for $5 \mathrm{~min}$ (initial denaturation), 42 cycles of $94{ }^{\circ} \mathrm{C}$ for $1 \mathrm{~min}, 52{ }^{\circ} \mathrm{C}$ for $1.5 \mathrm{~min}$ and $72{ }^{\circ} \mathrm{C}$ for $2 \mathrm{~min}$, and a final extension at $72{ }^{\circ} \mathrm{C}$ for $10 \mathrm{~min}$. Amplified products were detected by ultraviolet light after electrophoresis in $1.2 \%$ agarose gel stained with ethidium bromide.

\section{Establishment of hairy roots and HPLC analysis}

Hairy roots of 3 weeks culture were subcultured into hormone-free MS liquid medium. The cultures were maintained at $90 \mathrm{rpm}$ in an orbital shaker (LM-570RD, YIHDER $^{\circledR}$ Thiwan) under $25 \pm 2{ }^{\circ} \mathrm{C}$ in $24 \mathrm{~h}$ darkness. Hairy roots were subcultured to fresh media every 7 days of culture.

Dried hairy roots were ground into fine powder $(1 \mathrm{~g}$ DW) extracted with methanol $(10 \mathrm{ml})$ under sonication for $30 \mathrm{~min}$. HPLC analysis of withanolides was performed according to a modified method of Sivanandhan et al. (2012). The analytical HPLC experiments were performed with High-Performance Liquid Chromatography (LC 2006 System, Japan ${ }^{\circledR}$ ) equipped with variable wavelength detector operating at $250 \mathrm{~nm}$. Separations were carried out with reverse-phase ODSSUPELCOSILTM column C18 $(25 \mathrm{~cm} \times 4.6 \mathrm{~mm}, 5 \mu \mathrm{m}$ particle $)$ with methanol:water (65:35) as an eluent at a flow rate of $1 \mathrm{ml} \mathrm{min}^{-1}$. Withaferin A and withanolide A standards were procured from Natural Remedies (Bengaluru, Karnataka, India).

\section{Statistical analysis}

Each treatment comprised 25 explants in replicates of three. The number of explants responded, the number of hairy roots, and percentage of transformation efficiency were recorded after 3 weeks of culture. All data were subjected to one-way ANOVA followed by the statistical significance test. The significant difference among the mean \pm standard error (SE) was carried out using Duncan's Multiple range test and significance level of $P<0.05$ (IBM, SPSS ver. 19).

\section{Results and discussion}

\section{Effect of $A$. rhizogenes strains on hairy root induction}

A. rhizogenes strains R1000, MTCC 2364, and MTCC 532 were used to determine the transformation efficiency toward hairy root induction in $W$. somnifera. These three strains showed different levels of infection and there were no hairy roots from control explants. A rhizogenes strain R1000 was found to be more effective for inducing hairy roots and showed maximum $50.6 \%$ transformation efficiency (Figs. 1a, 2). MTCC 2364 showed less efficiency $(29.3 \%)$ than R1000, and MTCC 532 was the least efficient $(18.6 \%)$. Influence of A. rhizogenes strain on hairy root induction frequency has been documented earlier in several plant species (Sujatha et al. 2013). R1000 strain was widely used for hairy root induction in many plants such as Torenia foarnieri (Tao and Li 2006), Gentiana macrophylla (Tiwari et al. 2007), and Artemisia vulgaris (Sujatha et al. 2013). The infection process is highly dependent on successful transfer of Ri T-DNA into the host cells (Mariashibu et al. 2013). This intrinsic capacity of Ri plasmid must be higher in R1000 when compared to other strains as inferred by other reports also (Wang and Fang 1998).

\section{Effect of heat treatment on hairy root induction}

Heat treatment is a common approach in tissue culture and Agrobacterium-mediated transformation studies in several plant species (Hiei et al. 2006). The significant enhancement of Agrobactreium transformation efficiency using heat treatment was achieved in banana (Khanna et al. 2004) and sorghum (Gurel et al. 2009). In the present study, we analyzed for the first time to evaluate the effect of heat treatment toward the transformation efficiency of $A$. rhizogenes in $W$. somnifera. The explants were infected with A. rhizogenes at various temperature of $39,41,43$, or $45^{\circ} \mathrm{C}$ and duration of $3,5,7$, or $10 \mathrm{~min}$. Our preliminary results showed that $41{ }^{\circ} \mathrm{C}$ heat treatment for 5 min was the most effective for higher percentage $(76.0 \%)$ of hairy root induction (Figs. 1b, 3a). When heat treatment at $41{ }^{\circ} \mathrm{C}$ was extended from 5 to 7 or $10 \mathrm{~min}$, there was a drastic reduction in the hairy root induction frequency. 
Fig. 1 Hairy root culture of $W$. somnifera. a Hairy root initiation from leaf explant after co-cultivation with $A$. rhizogenes strain R1000 (after 7 days). b Hairy root proliferation after 3 weeks in heat-treated culture $\left(41{ }^{\circ} \mathrm{C}\right.$ for 5 min). c Hairy root proliferation after 3 weeks in sonication $(15 \mathrm{~s})$ and heat treatment $\left(41^{\circ} \mathrm{C}\right.$ for $\left.5 \mathrm{~min}\right)$. d Proliferative mass accumulation of hairy roots cultured in hormone-free MS basal liquid medium (after 4 weeks of culture)
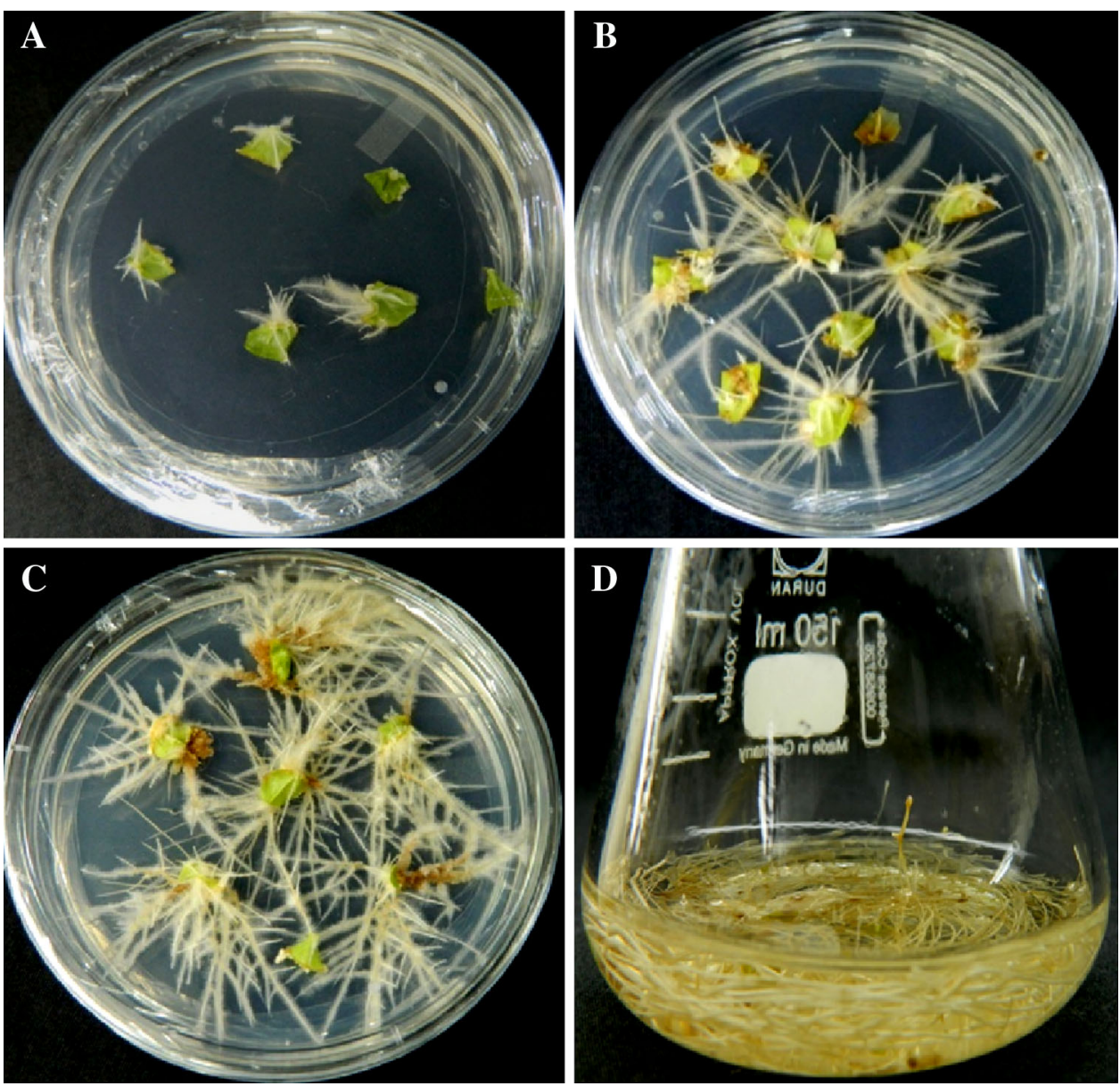

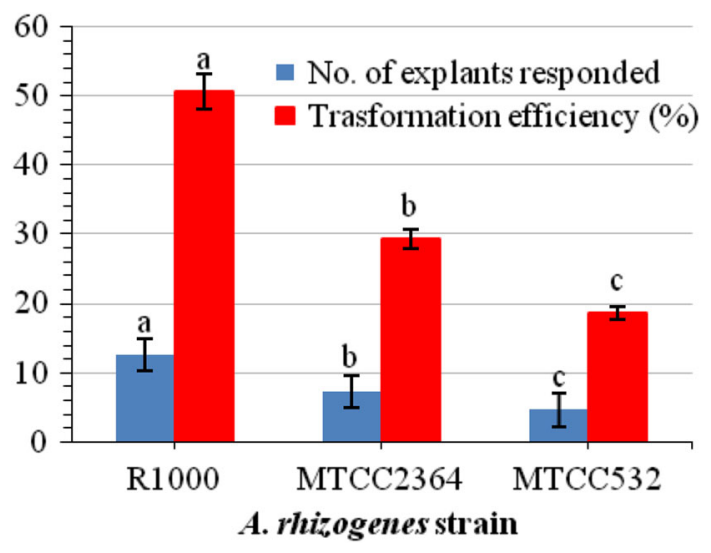

Fig. 2 Efficiency of A. rhizogenes strain on hairy root induction. Data represented mean $\pm \mathrm{SE}$, of the three independent experiments. Mean values showed by different letters are significantly different at $P<0.05(\mathrm{DMRT})$

\section{Effect of sonication and heat treatment on hairy root induction}

Sonication-assisted Agrobacterium-mediated transformation is an improved approach to enhance the efficiency of Agrobacterium-mediated transformation of many low or previously known to be non-susceptible plant species (Trick and Finner 1997, 1998; Subramanyam et al. 2011). The enhanced transformation efficiency using SAAT probably results from thousands of microwounds on and below the surface of the target tissue caused by sonication. These microwounds facilitate Agrobacterium to penetrate deeper into the target tissue and provide efficient delivery of T-DNA for transformation (Liu et al. 2005; Subramanyam et al. 2011). Subramanyam et al. (2011) and Mariashibu et al. (2013) successfully obtained transformed plants by sonicating target tissues with A. tumifaciens cultures. No reports on transformation with SAAT method are available for hairy root induction in W. somnifera. We investigated the influence of sonication on transformation efficiency of $A$. rhizogenes in $W$. somnifera by sonication of explants in suspension for different time duration of 5 , 10,15 , or $20 \mathrm{~s}$ followed by heat treatment of $41{ }^{\circ} \mathrm{C}$ for $5 \mathrm{~min}$. Among the different time durations, a $15 \mathrm{~s}$ sonication proved to be the best and produced $93.3 \%$ of transformation efficiency after 3 weeks (Figs. 1c, 3b). Beyond 5,10 , or $20 \mathrm{~s}$, percentage of transformation efficiency was reduced. This might be because of excess tissue damage due to prolonged sonication. 


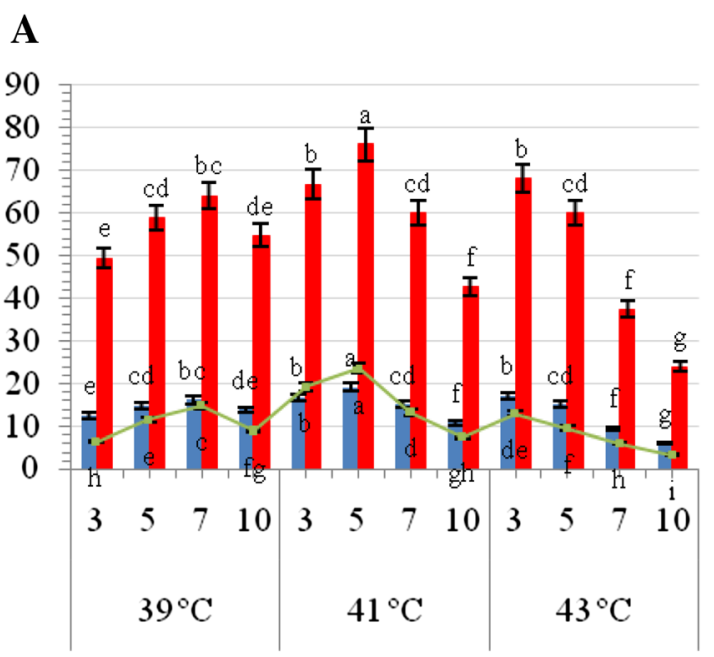

Heat treatment $\left({ }^{\circ} \mathrm{C} / \mathrm{min}\right)$

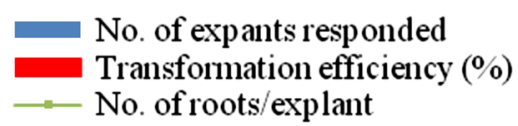

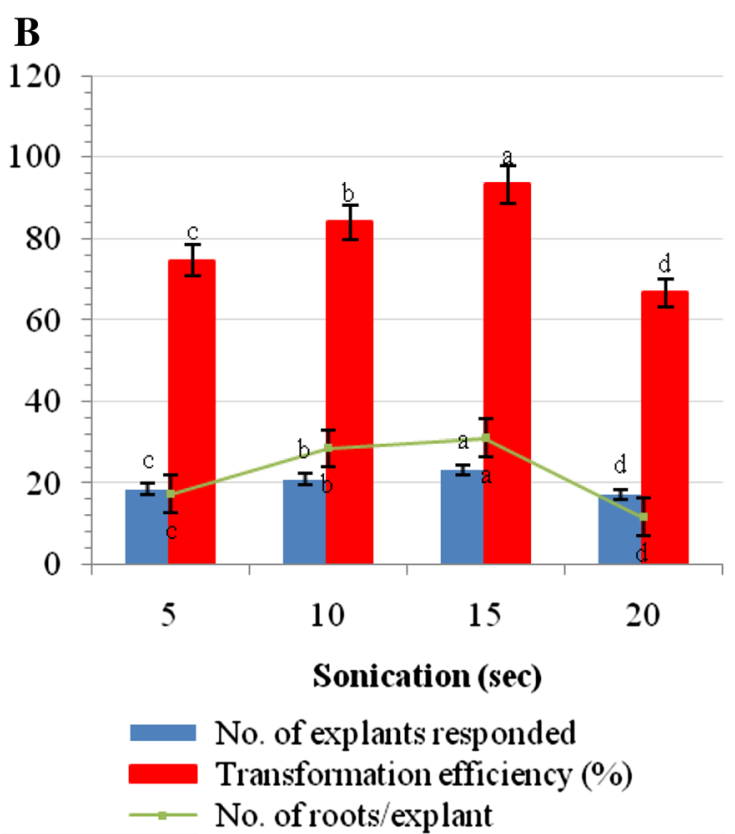

Fig. 3 a Influence of heat treatment on transformation efficiency and $\mathbf{b}$ sonication on hairy root induction. Data represented mean \pm SE, of the three independent experiments. Mean values showed by different letters are significantly different at $P<0.05$ (DMRT)

A. rhizogenes-mediated hairy root induction has been documented earlier in W. somnifera by several authors (Ray et al. 1996; Kumar et al. 2005; Sivanandhan et al. 2014). Ray et al. (1996) reported that the withanolide D productivity was higher in $\left(0.181 \mathrm{mg} \mathrm{l}^{-1}\right.$ day $\left.^{-1}\right)$ transformed roots than in untransformed roots $\left(0.026 \mathrm{mg}^{-1}\right.$ day $^{-1}$ ). Kumar et al. (2005) observed the antioxidant activity in A. rhizogenes transformed hairy roots. Both of them failed to analyze the hairy root induction frequencies in W. somnifera. Recently, Sivanandhan et al. (2014) observed that the leaf explants of $W$. somnifera showed higher $(88.4 \%)$ frequency of hairy root induction than in cotyledon explants $(64.2 \%)$ when co-cultivated with $A$. rhizogenes strain R1000. The present study reports that the highest transformation efficiency $(93.3 \%)$ was obtained when the leaf explants of $W$. somnifera were subjected to sonication and heat treatment during transformation with $A$. rhizogenes. This protocol can be used for hairy root production on a large scale at a faster rate compared to previous methods of hairy root induction in W. somnifera.

\section{PCR analysis for confirmation of transgenic status}

In the present study, to confirm the integration of T-DNA from the $A$. rhizogenes into the hairy roots, $r o l \mathrm{~B}$ gene was tested using rol B-specific primers (Fig. 4). A. rhizogenes transfers two independent T-DNAs $\left(\mathrm{T}_{\mathrm{L}}\right.$-DNA and $\mathrm{T}_{\mathrm{R}^{-}}$ DNA) to the host plant genome (Nilsson and Olsson 1997). $\mathrm{T}_{\mathrm{L}}$-DNA to be the most important virulent factor and it is essential to induce hairy roots (Sujatha et al. 2013). The

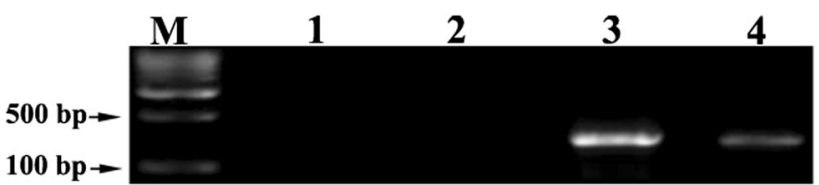

Fig. 4 PCR detection of rol B gene in hairy roots. Lane $M$ molecular weight marker (1000 bp); lane 1, water control; lane 2, negative control (non-transformed roots); lane 3, rol B positive control (Ri plasmid); lane 4, rol $\mathrm{B}$ transformed hairy roots

sequence analysis of $T_{L}$-DNA identified 18 open reading frames (ORF), four of which are essential for hairy root

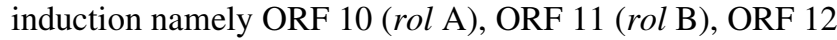
(rol C), and ORF (rol D) (Georgiev et al. 2011). White et al. (1985) identified that rol B has a central role in pathogenecity. In this study, DNA from agropine type of $A$. rhizogenes strain R1000 served as the positive control and normal roots of in vitro plants served as the negative control. PCR results showed that all the hairy root lines contained $423 \mathrm{bp}$ rol B gene fragment, which were the parts of T-DNA of Ri plasmid (Fig. 4).

\section{Establishment of hairy root culture and HPLC analysis}

The potential growth of hairy roots in liquid (MS) shakeflask culture without hormone was successfully achieved in the present study (Fig. 1d). The HPLC profile of withaferin A and withanolide A from the hairy root of W. somnifera is depicted in Fig. 5a-c. The results confirmed a considerable 

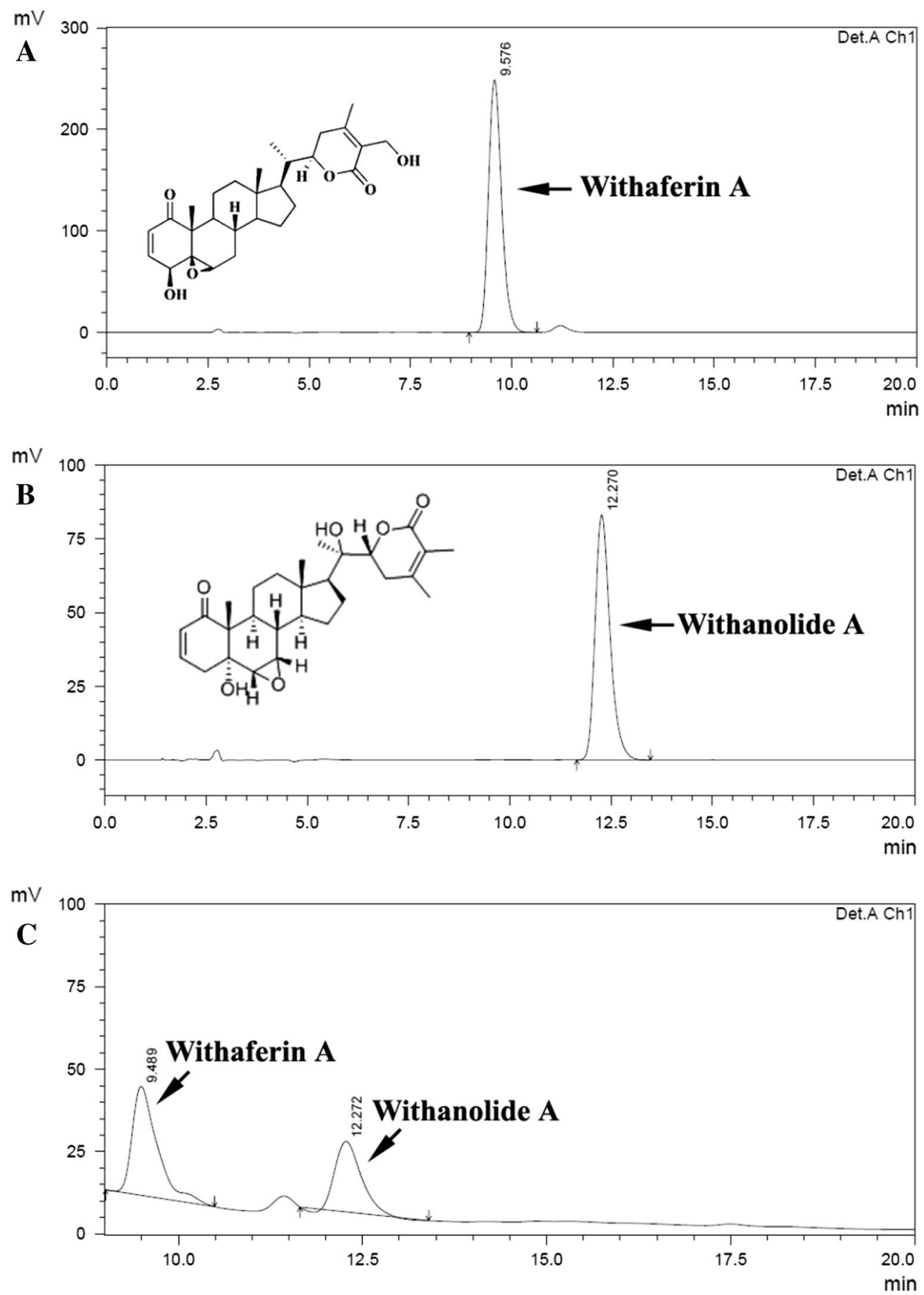

Fig. 5 HPLC analysis of withanolide production in hairy root culture. a Standard withaferin A, b standard withanolide A and $\mathbf{c}$ Withanolides (withaferin A and withanolide A) from sonication ( $15 \mathrm{~s}$ ) and heat treatment $\left(41^{\circ} \mathrm{C}\right.$ for $5 \mathrm{~min}$ )-assisted hairy roots culture

amount of withaferin $\mathrm{A}\left(6.17 \mathrm{mg} \mathrm{g} \mathrm{l^{-1 }} \mathrm{DW}\right)$ and withanolide A (3.82 $\left.\mathrm{mg} \mathrm{g} \mathrm{l}^{-1} \mathrm{DW}\right)$ in the hairy roots, which were identified with peaks corresponding to standard withanolide markers. The accumulation of higher levels of withanolides in hairy roots could be due to the effect of T-DNA integration on the secondary metabolite production as reported in many plant species (Bulgakov 2008; Shkryl et al. 2008; Bansal et al. 2014). Although hairy roots of the Italian W. somnifera were induced by A. rhizogenes, they did not accumulate withanolides (Vitali et al. 1996). The present study found the presence of withanolides in transformed hairy root culture of the Indian $W$. somnifera produced using A. rhizogenes. Similarly, Bandyopadhyay et al. (2007) and Murthy et al. (2008) also reported the presence 
of withanolides in transformed hairy root cultures of Indian W. somnifera.

\section{Conclusion}

The highest percentage of hairy root induction was obtained with $A$. rhizogenes strain R1000 into W. somnifera leaf explants through $15 \mathrm{~s}$ sonication and heat treatment at $41{ }^{\circ} \mathrm{C}$ for $5 \mathrm{~min}$. Furthermore, these transformed hairy roots are able to produce bioactive compounds. To the best of our knowledge, this is the first report of $A$. rhizogenesmediated transformation using sonication and heat treatment in $W$. somnifera. This system provides an efficient tool for hairy root production and is useful for commercial production of withanolide under in vitro condition.

Acknowledgments Dr. A. Shajahan is thankful to the University Grants Commissions (UGC), Govt. of India, New Delhi for the financial support through UGC Major Research Project (F. No. 42-946/ 2013-SR). The authors also thank DST, Govt. of India for providing facilities through DST-FIST program.

Conflict of interest The authors declare that they have no conflict of interest.

Open Access This article is distributed under the terms of the Creative Commons Attribution License which permits any use, distribution, and reproduction in any medium, provided the original author(s) and the source are credited.

\section{References}

Ali M, Shauaib M, Ansari SH (1997) Withanolides from the stem bark of Withania somnifera. Phytochem 44:1163-1168

Aslam A, Mohamed Rafi K, Kathiravan K, Shajahan A (2010) Classbased stratification matrix for physical leaf traits in phenetic relations of Withania somnifera (L.) Dunal accessions. Plant Syst Evol 288:99-111

Bandyopadhyay M, Jha S, Tepfer D (2007) Changes in morphological phenotypes and withanolide composition of Ri-transformed roots of Withania somnifera. Plant Cell Rep 26:599-609

Bansal M, Kumar A, Reddy MS (2014) Influence of Agrobacterium rhizogenes strains on hairy root induction and 'bacoside $\mathrm{A}$ ' production from Bacopa monnieri (L.) Wettst. Acta Physiol. doi:10.1007/s11738-014-1650-5

Bulgakov VP (2008) Functions of rol genes in plant secondary metabolism. Biotechnol Adv 26:318-324

Bulgakov VP, Khodakovskaya MV, Labetskaya NV, Tchernoded GK, Zhuravlev YN (1998) The impact of plant rol C oncogene on ginsenoside production by ginseng hairy root cultures. Phytochem 49:1929-1934

Chatterjee S, Srivastava S, Khalid A, Singh N, Sangwan RS, Sidhu OP, Roy R, Khetrapal CL, Tuli R (2010) Comprehensive metabolic fingerprinting of Withania somnifera leaf and root extracts. Phytochem 71:1085-1094

Choudhary MI, Yousuf S, Nawaz SA, Ahmed S, ur-Rahman A (2004) Cholinesterase inhibiting withanolides from Withania somnifera. Chem Pharm Bull 52:1358-1361
Choudhary MI, Nawaz SA, Zaheer-ul-Haq Lodhi MA, Ghayur MN, Jalil S, Riaz N, Yousuf S, Malik A, Gilani AH, ur-Rahman A (2005) Withanolides a new class of natural cholinesterase inhibitors with calcium antagonistic properties. Biochem Biophys Res Commun 334:277-287

Choudhary MI, Yousuf S, ur-Rahman A (2013) Withanolide: chemistry and antitumor activity. In: Ramawat KG, Mérillon (eds) Natural products, Springer, Berlin pp 3465-3495

Fu CX, Zhao DX, Xue XF, Jin ZP, Ma FS (2005) Transformation of Saussurea involucrate by Agrobacterium rhizogenes: hairy root induction and syringing production. Process Biochem 40:3789-3794

Georgiev MI, Ludwig-Müller J, Alipieva K, Lippert A (2011) Sonication-assisted Agrobacterium rhizogenes-mediated transformation of Verbascum xanthophoeniceum Griseb. for bioactive metabolite accumulation. Plant Cell Rep 30:859-866

Giri A, Narasu ML (2000) Transgenic hairy roots: recent trends and applications. Biotechnol Adv 18:1-22

Gurel S, Gurel E, Kaur R, Wong J, Meng L, Tan H-Q, Lemaux PQ (2009) Efficient, reproducible Agrobacterium-mediated transformation of sorghum using heat treatment of immature embryos. Plant Cell Rep 28:429-444

Hiei Y, Ishida Y, Kasaoka K, Komari T (2006) Improved frequency of transformation in rice and maize by treatment of immature embryos with centrifugation and heat prior to infection with Agrobacterium tumefaciens. Plant Cell Tiss Organ Cult 87:233-243

Hu ZB, Du M (2006) Hairy root and its application in plant genetic engineering. J Integr Plant Biol 48:121-127

Jayaprakasam B, Nair MG (2003) Cyclooxygenase-2 enzyme inhibitory withanolides from Withania somnifera leaves. Tetrahedron 59:841-849

Khanna H, Becker D, Kleidon J, Dale J (2004) Centrifugation Assisted Agrobacterium tumefaciens-mediated Transformation (CAAT) of embryogenic cell suspensions of banana (Musa spp. Cavendish AAA and Lady finger AAB). Mol Breed 14:239-252

Kiasalari Z, Khalili M, Aghaei M (2009) Effects of Withania somnifera on levels of sex hormones in the diabetic male rats. Iranian J Reprod Med 7:163-168

Kuboyama T, Tohda C, Komatsu K (2005) Neuritic regeneration and synaptic reconstruction induced by withanolide $\mathrm{A}$. Br J Pharmocol 144:961-971

Kumar V, Murthy KN, Bhamid S, Sudha CG, Ravishankar GA (2005) Genetically modified hairy roots of Withania somnifera Dunal: a potent source of rejuvenating principles. Rejuvenation Res $8: 37-45$

Le Flem-Bonhomme V, Laurain-Mattar D, Fliniaux MA (2004) Hairy root induction of Papaver somniferum var. album, a difficult to transform plant, by Agrobacterium rhizogenes LBA 9402. Planta 218:890-893

Liu Z, Park B-J, Kanno A, Kameya T (2005) The novel use of a combination of sonication and vacuum infiltration in Agrobactrium-mediated transformation of kidney been (Phaseolus vulgaris L.) with lea gene. Mol Breed 16:189-197

Mariashibu TS, Subramanyam K, Arun M, Mayavan S, Rajesh M, Theboral J, Manickavasagam M, Ganapathi A (2013) Vacuum infiltration enhances the Agrobacterium-mediated genetic transformation in Indian soybean cultivars. Acta Physiol Plant 35:41-54

Maurya R, Akanksha J, Singh AB, Srivastava AK (2008) Coaguanolide, a withanolide form Withania coagulans fruits and antihyperglycemic activity. Bioorg Med Chem Lett 18:6534-6537

Mohamed Rafi K, Aslam A, Kohila S, Tanweer J, Shajahan A (2010) Direct rhizogenesis from in vitro leaves of Withania somnifera (L.) Dunal. Indian J Plant Physiol 15:172-175 
Murashige T, Skoog F (1962) A revised medium for rapid growth and bioassays with tobacco tissue cultures. Physiol Plant 15:473-497

Murthy HN, Dijkstra C, Anthony P, White DA, Davey MR, Power JB, Hahn EJ, Paek KY (2008) Establishment of Withania somnifera Hairy Root Cultures for the Production of Withanolide A. J Int Plant Biol 50:975-981

Nilsson O, Olsson O (1997) Getting to the root: the role of the Agrobacterium rhizogenes rol-genes in the formation of hairy roots. Physiol Plant 100:463-473

Praveen N, Murthy HN (2010) Production of withanolide-A from adventitious root cultures of Withania somnifera. Acta Physiol Plant 32:1017-1022

Praveen N, Murthy HN (2012) Synthesis of withanolide A depends on carbon source and medium $\mathrm{pH}$ in hairy root cultures of Withania somnifera. Indust Crops Product 35:241-243

Ray S, Ghosh B, Sen S, Jha S (1996) Withanolide production by root cultures of Withania somnifera transformed with Agrobacterium rhizogenes. Planta Med 62:571-573

Sabir F, Sangwan RS, Singh J, Misra LN, Pathak N, Sangwan NS (2011) Biotransformation of withanolides by cell suspension cultures of Withania somnifera (Dunal). Plant Biotech Rep 5:127-134

Sangwan WS, Chaurasiya ND, Lal P, Misra L, Uniyal GC, Tuli R, Sangwan NS (2007) Withanolide A bigeneration in in vitro shoot culture of Ashwagandha (Withania somnifera Dunal), a main medicinal plant in ayurveda. Chem Pharm Bull 55:1371-1375

Saravanakumar A, Aslam A, Shajahan A (2012) Development and optimization of hairy root culture systems in Withania somnifera (L) Dunal for withaferin-A production. Afri J Biotech 11:16412-16420

Shkryl YN, Veremeichik GN, Bulgakov VP, Tchernoded GK, Mischenko NP, Fedoreyev SA, Zhuravlev YN (2008) Individual and combined effect of the rol A, B and C genes on anthraquinone production in Rubia cordifolia transformed calli. Biotechnol Bioeng 100:118-125

Sivanandhan G, Arun M, Mayavan S, Rajesh M, Mariashibu TS, Manickavasagam M, Selvaraj N, Ganapathi A (2012) Chitosan enhances withanolides production in adventitious root cultures of Withania somnifera (L.) Dunal. Indust Crops Product 37:124-129

Sivanandhan G, Kapil Dev G, Jayaraj M, Rajesh M, Arjunan A, Muthuselvam M, Manickavasagam M, Selvaraj N, Ganapathi A (2013) Increased production of withanolide A, withanone, and withaferin A in hairy root cultures of Withania somnifera (L.) Dunal elicited with methyl jasmonate and salicylic acid. Plant Cell Tiss Organ Cult 114:121-129

Sivanandhan G, Selvaraj N, Ganapathi A, Manickavasagam M (2014) An efficient hairy root culture system for Withania somnifera. African J Biotech 13:4141-4147

Subramanyam K, Subramanyam K, Sailaja KV, Srinivasulu M, Lakshmidevi K (2011) Highly efficient Agrobacterium-mediated transformation of banana cv. Rasthali (AAB) via sonication and vacuum infiltration. Plant Cell Rep 30:425-436

Sujatha G, Zdravković-Korać S, Calić D, Flamini G, Ranjitha Kumari BD (2013) High-efficiency Agrobacterium rhizogenes-mediated genetic transformation in Artemisia vulgaris: hairy root production and essential oil analysis. Indust Crops Product 44:643-652

Tao J, Li L (2006) Genetic transformation of Torenia fournieri L. mediated by Agrobacterium rhizogenes. South Afr J Bot 72:211-216

Tiwari RK, Trivedi M, Guang ZC, Guo GQ, Zheng GC (2007) Genetic transformation of Gentiana macrophylla with Agrobacterium rhizogenes: growth and production of secoiridoid glucoside gentiopicroside in transformed hairy root cultures. Plant Cell Rep 26:199-210

Trick HN, Finner JJ (1997) SAAT: sonication-assisted Agrobacterium-mediated transformation. Transgenic Res 6:329-337

Trick HN, Finner JJ (1998) Sonication-assisted Agrobacteriummediated transformation of soybean [Glycine $\max (\mathrm{L}$.) Merrill] embryogenic suspension culture tissue. Plant Cell Rep $17: 482-488$

Vitali G, Conte L, Nicoletti M (1996) Withanolide composition and in vitro culture of Italian Withania somnifera. Planta Med 62:287-288

Wang GL, Fang HJ (1998) Mechanism and technology of plant genetic engineering. Science Publisher, Beijing

White FF, Taylor BH, Huffman GA, Gordon MP, Nester EW (1985) Molecular and genetic analysis of the transformed DNA regions of the root-inducing plasmid of Agrobacterium rhizogenes. J Bacteriol 164:33-44

Zhao DX, Fu CX, Chen YQ, Ma FS (2004) Transformation of Saussurea medusa for hairy roots and jaceosidin production. Plant Cell Rep 23:468-474 